\title{
The Negotiation of Interactive Frames and Discourse Identities in China's Rural Insurance Sales Interactions
}

\author{
Weichao Wang ${ }^{1} \&$ Huan Peng ${ }^{2}$ \\ ${ }^{1}$ School of English for International Business, Guangdong University of Foreign Studies, Guangzhou, China \\ ${ }^{2}$ School of Foreign Studies, Guangzhou University, Guangzhou, China \\ Correspondence: Huan Peng, School of Foreign Studies, Guangzhou University, Guangzhou, 510420, China. Tel: \\ 020-39366711. E-mail: vivianpennw@163.com
}

Received: March 13, 2017 Accepted: May 28, 2017 Online Published: May 31, 2017

doi: 10.5539/elt.v10n7p61 URL: http://doi.org/10.5539/elt.v10n7p61

\begin{abstract}
This paper analyzes dialogues between insurance sales agents and their clients in transformational rural China from the perspective of interactive frames, footings and discourse identities. Through the analysis of three types of talk, namely, friendship talk, institutional talk and task-oriented talk, the ambiguous and conflicting identities that both agents and clients adopt in the conversations are captured and described. It then describes and analyzes the dynamics of the mobilization and strategic management of relative identities that both parties assume and employ in order to resolve conflicts, justify oneself and resume control. The analysis further probes into the transforming nature of the modern Chinese rural society, where old and traditional value systems have, to a large extent, been shattered, while new value systems are yet to be established.
\end{abstract}

Keywords: frame of reference, identity, insurance sales, transformation, rural China

\section{Introduction}

This paper analyzes dialogues between insurance sales agents and their clients in transformational rural China from the perspective of interactive frames, footings and discourse identities. Specifically, it studies how both agents and clients mobilize the interactional devices available to them in order to invoke the identities favorable to their respective advantages. Through the analysis, the dynamics of agent-client interaction is captured and described. In addition, this paper includes a discussion on Guanxi (interpersonal relationships) and the transformation of China's rural society at large.

Insurance is a core institution in a society increasingly organized around managing risk. As Beck (1992) argues, a risk-based society is also an individual society. The utilization of insurance sales agents' identities for the purpose of achieving economic goals interact with key contemporary social tendencies. These include the responsibilization of the individual consumer, the erosion of the social safety net, fragmentation, individualism and the attenuation of family ties, the growth of a "flexible" labor force, and the downgrading of regulatory responsibility by the government. Until recently, the social dynamics of insurance has received surprisingly little attention from social scientists (Strange, 1996; Baker \& Simon, 2013). Most academic research on insurance has been conducted by economists and researchers in business and finance. Nonetheless, insurance studies have recently emerged as a blossoming field for other researchers, especially in sociology, socio-legal studies and criminology (Baker \& Simon, 2013; Ericson \& Doyle, 2003; Ericson et al., 2003; Ericson \& Doyle, 2004a; 2004b; 2004c). In China, research on insurance is mostly conducted from economic, business or financial perspectives; the primary focus is to investigate the current situation in China's insurance industry and offer suggestions to improve the efficiency and profitability of the insurance institutions from political, economic and marketing perspectives (Sheng, 2009; Zhu, 2009; Hu \& Wang, 2009; Shu \& Li, 2006; Yuan, 2008; Guo, 2009; Li, 2008; Ding, 2008; Cao, 2009; Xu, 2009). An emerging research focus is to adopt a sociological perspective and put insurance into social, economic and cultural contexts, and then study the inter-relationship among these to consider the interaction between insurance and many other social, economic and cultural factors (Hu \& Wang, 2009). Such studies are, however, mainly focusing on the macro aspects and generally lack empirical evidence. Several issues can be identified in this previous research. Firstly, this research is focusing on general aspects and adopts a top-down approach. Secondly, most of this research is based on academic reasoning and previous literature, with very limited empirical evidence, which make the results less convincing. Thirdly, the stance taken 
is on the behalf of the organizations, thus neglecting the interaction between the agents and their clients. The participants are seen as strictly passive recipients of the actions, which might not reflect the reality of these processes. These gaps in the literature warrant this study, which investigates micro-aspect of insurance sales interactions in transformational rural China.

Based on the shortcomings identified above, there is an urgent and imperative need to study insurance based on sociological theories or concepts and to analyze in greater detail, offering empirical evidence. The dialogues between insurance sales agents and clients, a contemporary research genre situated on the boundary between public/organizational and promotional paradigms, are relatively under-researched and marginalized. The present study is intended to fill the gap in the literature and strike a balance between macro- and micro- studies for the purpose of revealing the hidden world of insurance sales discourse in transformational China's rural areas.

Goffman's participation framework (1981) is made up of "a set of positions which individuals within perceptual range of an utterance may take in relation to what is said" (Schiffrin, 1990). Participation frameworks are negotiated during the interpersonal relationship. They are the result of actions and alignments that the individuals adopt towards themselves and others under certain circumstances. They are the result of the various footings used by the participants (Goffman, 1981).

The notion of participant roles has been discussed by many linguists, most forcefully in the concept of discourse identity (Scollon, 2001), which is defined as the role/roles a person can claim with degree and range of power, comprising the productive and receptive roles demonstrated, intersecting with the socio-interactive roles a person has power to enact. In the context of the present study, the discourse identities of the participants involved are a combination of those entitled by the social identities of friends and salespersons/clients. It is only possible to negotiate social identities by adjusting discourse identities, not negotiate discourse identities by adjusting social identities, since discourse identities are in essence a "tool" for achieving social identities. By actively engaging in an interaction, participants will cooperatively maintain and adjust their discourse identities in order to negotiate their social identities. It should be noted that a participant can adjust not only his/her own discourse identities but also those of his/her partner in an interaction.

The sociological concepts of frame and footing do not focus on language; they are insufficiently defined in the sense that the role of language is still unclear in the inferring process. Gumperz's $(1982,1992)$ more fine-grained linguistic concept of contextualization cues, dealing with the weaknesses of the sociological notion of frames, is trying to mitigate this shortcoming. The key notion of Gumperz's work is to "account for our ability to interpret what participants intend to convey in everyday communicative practice" (Gumperz, 2001). "Contextualization cues, along with other indexical signs, serve to retrieve the frames that channel the interpretive process" (Prevignano \& di Luzio, 2003).

Moreover, as Drew and Heritage (1992) claim, interaction is a dynamic process and language is a crucial resource in managing social relations at work. Based on this, an interesting question emerges: How is language employed to facilitate insurance sales in rural China?

\section{Methods}

Based on ten authentic, naturally occurring conversations between insurance sales agents and their prospective clients, the chief methodology used in this study is discourse analysis, focusing on conversational analysis at the micro-analytic level.

\subsection{Data Collection}

In sociolinguistics or studies of business English (Cameron et al., 1988; Planken, 2005) and cross-cultural/intercultural pragmatic studies (Bargiela et al., 2009), data are generally collected in a controlled and selective manner, and the focus is always on one or several types of speech acts. As Huo (2004) notes, it is preferred that the type of data for such research be collected in a natural, uncontrolled way in order to not be confined to a certain type of data, but instead include all aspects of dynamics. As Sacks et al. (1974), Heritage (1984), Jefferson (2004) and many other researchers (Duranti, 1998; Heritage, 1984; Zimmerman, 1988) point out, many analysts have studied mundane social action and have achieved desired results in such areas of discourse as the turn-around of organizations (Boden, 1983; Roger, 1989; Schegloff, 2000a, 2001) and the over-haul of organizations (Schegloff 2000b). Other scholars have focused on the structure of social interaction (Eggins, 1997; Yang, 1994; Lin, 2004), intra-cultural communication in various languages (Hayashi, 2003) and intercultural communication studies (Cheng, 2003; Scollon \& Scollon, 2001; Tanaka, 1999). Regarding studies using Chinese data, most focus on Cantonese (Kong, 2001, 2002, 2003; Luke, 1990). However, their findings on Chinese communication may not satisfactorily explain the interaction pattern and linguistic features specific to 
the Mainland Chinese (mainly speaking Mandarin) due to the data they collect and use for their analysis.

The data collected for this study come from recordings of conversations which took place between 2009 and 2013, about 80 hours from 50 conversations) between insurance sales agents and their prospective clients at their homes, tea houses, meeting rooms or other locations. The selected data for the analysis consist of ten conversations between five agents and their clients, while other conversations were used for triangulation purposes. The conversations were transcribed by the author of this study according to the conventions of conversation analysis for discourse analysis purposes. Some of the conversations involve two agents (the more experienced agent accompanies a less experienced colleague on client visits), while other conversations involve more than one client (their families or relatives may be present). In general, some conversations involve two participants; others may involve several participants since the conversations are rather informal in nature and the prospects' relatives or friends may be present during the conversations. Their names, and some specific names of their products and their prices, were replaced by pseudonyms or " $\mathrm{X}$ "s.

\subsection{Procedures of Analysis}

The procedures of analysis mainly start with the transcriptions, followed by transcription studies to identify recurrent phenomena across the transcribed conversations. The procedures include:

Listening to the data, classifying the data, selecting the data, transcribing the selected data, studying the data for recurrent phenomena, in-depth discourse analysis of the excerpts by focusing on the phenomena, making cultural and linguistic interpretations of the analyzed phenomena, studying the interpersonal preferences and generating implications from the analysis.

The analysis is mainly qualitative, but is supported by a quantitative approach based on numerical evidence. A qualitative approach was applied first with the aim to discover and reconstruct patterns in insurance sales discourse. The data were examined for emerging patterns and language use that reflected the most striking features of the Chinese insurance sales agents in terms of discourse conventions, cultural patterns, and also values and linguistic manifestations present in the sales process. The qualitative findings provide background information on the context and subject, acting as an aid for scale construction (Punch, 1998). The quantitative findings provide the basis for a qualitative study which aims to generate and frame the preferred patterns and linguistic choice in insurance sales discourse.

\section{The Analysis and Results}

This part offers the context of the interaction, then presents and analyzes the confrontation, mediation and co-construction of different identities; it then further discusses different frames as represented by different interactive frames, and thereafter presents the implications.

\subsection{The Context of the Interactions}

The interaction analyzed below is a reconstructed conversation between an experienced insurance sales agent and a prospective client in the client's home. The experienced agent is a female in her early 30 s, with more than six years' experience in insurance sales in the local area. With her hard work and devotion, she has an excellent sales volume and has received financial incentives and other fringe benefits the company offers, such as free tours to tourist spots, etc. She is known as the star agent of the local branch and enjoys a high reputation in the company. She is well-aware that her income and well-being are largely dependent on her efforts and skills to make the sales. On the other hand, the prospective client is rather new to the aspects of insurance but has some interest in understanding the necessity of insurance due to the fact that he has been rather successful in his Guangdong business. (He is involved in a trading business, purchasing products from remote areas and selling them afterwards to restaurants in large cities.) The agent owns a kindergarten which the prospective client's daughter attends. The agent's husband is the well-regarded director of the village, and her father is a locally well-respected doctor. The two participants have met each other several times before the interaction takes place.

Some other agent-client interactions are also used for the quantitative analysis. The context across all the interactions is similar: The agents are locally respected and well-known people who are trying to make the sales. All of them have more than five years' experience. All the prospective clients have above- average income (when compared with the local standard) and enjoy prosperous lives. Most of the interactions take place at the clients' home. All participants are aware of being recorded during their interactions.

The relationship between the agent and the prospective client is rather complicated and ambiguous. On one hand, they are friends who are quite familiar with each other; on the other hand, the agent's income is based on the prospective client's decision in making the purchase and his possible recommendation of insurance to other friends or relatives. What is tricky here is that the agent needs to make efforts to make the sales and at the same 
time maintain the friendly relationship; while she does not have the authority or power of regulation and control, as manifested in employer-employee relationships. This is exactly why insurance sales agents often need to exploit the mediated interface between business and friendship by constantly intermingling friendships and business relationships.

The interaction can generally be divided into three phases. The first phase is the warming-up, when both parties mainly socialize to establish a harmonious atmosphere in preparation for the next stages. The second phase mainly focuses on task-oriented and institutional talk, with the agent managing to make the sales. This is the most interesting phase with constant mediation and contestation of frames and identities. The third phase is the closing part, normally focusing on friendship talk in order to end the interaction in a friendly and harmonious manner. The following analysis is mainly focused on the second phase, in which the participants' identities are at stake.

\subsection{Co-construction of Different Identities in Task-oriented Talk}

The dynamic management of identities is clearly captured in the mediation of different frames. This indicates that people's identities are not pre-determined identities, but discursively and cooperatively produced and managed. Also, these dynamics are constituted in and activated by the conversational dynamics, such as changes in footings and interactive frames, as well as discourse identities mentioned above.

By analyzing conversations between experienced insurance sales agents and their prospective clients, this study examines in detail how identities in insurance sales are interactively maintained, ratified and managed through changes in footing, mediation of different frames and discourse identities, rather than being imposed by one of the participants. Since power, trust and familiarity are inherent features of the interaction, the mediation of power between the agent and the prospect will also be examined and analyzed, as power in this kind of interaction is subject to negotiation, as noted earlier.

\subsection{The General Pattern of Agent-client Interaction}

The following reconstructed segment of the agent-client interaction offers an analysis into the interactive management of the participants' relative advantageous identities (Appendix). First, an overall pattern of agent-client interaction is presented, and then different segments are analyzed to produce a more detailed understanding.

This segment of an interaction between the agent and the client presents a rather complete structure of the shifts between different types of talks. From this segment of a long conversation, the sequence of the three types of talk already presented can be clearly seen. It initiates with friendship talk (turn 1-turn 6), then goes on with task-oriented talk (turn 9-10), institutional talk (turn 17-24), then, due to deadlock or hesitations, resumes friendship talk (turn 26), and finally it ends with friendship talk.

In general, friendship identity is often invoked by friendship talk at the beginning of interactions. This identity is useful in maintaining the interpersonal ties and downplaying the business-oriented aspects of the participants' activities. Agents may initiate institutional talk by invoking the corresponding identities in order to control and justify their actions. In the meantime, the client can invoke friendship talk to justify his or her action or inaction. The interactions always end with friendship talk to reinforce their friendship and rapport. The following table offers a summary of the sequences of the talk categories and their respective interactive functions in the agent/client interactions. 
Table 1. Sequence of talk categories and their respective interactive functions

\begin{tabular}{|c|c|c|c|}
\hline Sequence & Topics & Initiator & Interactional functions \\
\hline Friendship talk & Family, health, decoration & Agent or client & To create a friendly atmosphere \\
\hline Task-oriented talk & Institutional topics & Agent or client & \\
\hline Friendship talk & $\begin{array}{l}\text { Family, health, decorations, } \\
\text { etc. }\end{array}$ & Client & $\begin{array}{l}\text { To conduct business in a friendly } \\
\text { manner }\end{array}$ \\
\hline Or & $\begin{array}{l}\text { Family, health, decorations, } \\
\text { etc. }\end{array}$ & Client & Disinterest, resistance \\
\hline Institutional talk & $\begin{array}{l}\text { Advice-giving, } \\
\text { products }\end{array}$ & Agent & To resolve conflicts, resume control \\
\hline Task oriented talk & Institutional topics & Agent or client & $\begin{array}{l}\text { To conduct business in a friendly } \\
\text { manner }\end{array}$ \\
\hline Friendship talk & $\begin{array}{l}\text { Family, health, decorations, } \\
\text { next meeting time }\end{array}$ & Agent or client & $\begin{array}{l}\text { To end the interactions in a friendly } \\
\text { manner }\end{array}$ \\
\hline
\end{tabular}

\subsection{Interactive Management of Identities in Different Types of Talk}

In the three different types of talk, identities are interactively managed, contested and negotiated. The following presents the analysis of the negotiation of identities in different types of talks.

\subsubsection{Negotiation of Identity in Friendship Talk}

The following analyzes in detail the opening segment of the conversation; it is mainly concerned with the interactive management of identities in friendship talk, followed with some discussions on its socio-cultural implications.

A: agent; B: prospect

1) A: Taking a break at home today?

2) B: Yes, I have one day off at home.

3) A: Oh, teacher Liu is your brother-in-law?

4) B: Yes.

5) A: He used to be our teacher. (Pause, 1 second)

Oh, you have two children?

6) B: Yes, I stay home with them to help them with their studies. (Pause, half a second)

You work with the insurance company?

One of the distinctive features of this conversation is the interactive management of different identities of both parties to their respective advantage. To be more specific, from turn 1 to turn 6 presented above, the agent greets the prospective client with "Jintian Zaijia Xiuxi a" (Taking a break at home today?), which clearly indicates the intimate relationship between the agent and the prospect, since normally, Chinese people greet each other with "Chiguo lema" (Have you had your meal?) or "Dao Naer qua" (Where are you going?), which may be considered as personal or private topics. It serves an ice-breaking function. It is, of course, quite natural and normal for friends to greet each other, but when it comes to insurance sales, there are financial interests at stake, which must be treated with extreme caution. As one of the informants confesses: "It's very important to have a good start. The fact is that many people hold negative views towards insurance; they think insurance sales is about deceit. What we can do is to try our best to convince them to have trust in us, and then take it slowly. Once they start to believe in us, there shouldn't be too much of a problem. The key is: How can we convince them to have trust in us? Of course it's important how we do things. The other important aspect is about talking; first, talk them into it, then talk about wealth management, about insurance, etc." (Personal communication, November 6, 2012). Due to the overuse and over-exploitation of the agents' personal credibility, many local people have a negative opinion about insurance sales staff, to the point where such constraints even involve the agents' families or relatives. For example, a father of one of the insurance sales agents mentioned: "Sometimes it's really hard. You know, if you do things right, it's OK; if anything went wrong, you will certainly be blamed for 
everything! Sometimes they may not talk about it to your face, but behind your back, there will be a lot of gossip..." This segment of confession demonstrates the dilemma that most of the agents face. On one hand, they need to shoulder an enormous performance pressure from the insurance company, and the lure of the financial rewards stimulate them to further exploit their Guanxi network. On the other hand, the moral dilemma they face is that their actions do not only affect themselves, but also their close families and relatives. If they live in the local area, they are obliged to get along with other people. As one agent puts it "Let's see if I'll starve to death without selling insurance!" Similar frustration and desperation are quite prevalent among many of the other agents. Therefore, they need to manage their identities very carefully when talking with their prospective clients. One may argue that it is actually a matter of degree. Since it is crucial to understand whether the clients make the purchase decision on their free will, or whether the agent purposefully conceals any potential problems of the policy during the discussion and purposefully manipulates their familiarity with the clients and the clients' trust in the agents. Nonetheless, the authors of this study do not intend to impose any moral judgment on the agents; the primary objective is to study the dynamic and interactive management of identities in the process of insurance sales.

Then, in turn 3 and turn 5 above, the agent activates the friendship frame with "Liu Laoshi Yuanlai Nimen Han Jiefu hei?"'(Oh, teacher Liu is your brother-in-law, right?). Teacher Liu is a third party that both agent and client are familiar with, who here acts as the bridge to a closer and more intimate interaction. As was argued earlier, the Chinese society is a society of familiars, a "differentiated mode of association" (Fei, 2007; Zhai, 2007; Huang, 2004). Even though the agent and client are familiars already, if there is a trustworthy third party, the interaction becomes even more smooth and intimate, partly due to the fact that school teachers are considered a well-respected group of people with high status. In order to further strengthen the credibility of the agent, in turn 7, the agent draws the attention to another high-status person in the discussion, a locally well-known doctor: "Liudian de XXX... Woshi Ta Jiejie" (Do you know XXX in Liudian? I'm his sister). By saying this, the agent is establishing a credible image; that is, "I'm not only your friend, but also many renowned people can vouch for me, you can trust my credibility." The successful establishment of such an image would be greatly conducive to the successful conclusion of business. Most of the time, the actual sale is to a certain extent relying on such images. For most clients, the trust or confidence in the sales person is even more important than trust in product sold, as one of informant states: "If it was not for her, I won't buy it at all. I thought that since we are familiar and good friends, at least she won't lie to me." This statement expressly transmits the idea that the person selling the product is much more important than the product itself.

It may be argued whether or not this virtually blind trust would cause damage to the relationship among people in transformational rural China, if some agents exploit such resources in the sole pursuit of profits only to their own advantage. Such risks exist, but there are certain mechanisms working to avoid this from happening. The main reason is that in China, especially in rural China, a person is not considered as an individual. Instead, he or she is considered as being a part of a group, for example a family or a team; therefore being an integral part of something bigger. If the agent is doing something only for his or her own profit, then the reputation or success of the entire group would be damaged or sabotaged. The group may then respond negatively to such misbehavior. Therefore, it seems that there are underlying governing principles or hidden moral standards functioning to ensure the orderly interactions among people in the local environment, which will be discussed further in the discussion part.

\subsubsection{Negotiation of Identity in Institutional Talk}

The following section analyzes the negotiation of identity in institutional talk. The agent presents a professional image, while the prospective client shows signs of being more of a recipient.

As analyzed and argued in the last part, one of the features of institutional talk in insurance sales interactions in transformational rural China is characterized by the unequal contribution/length to the conversation. For example, turn 17 to turn 23 and turn 33 (The appendix shows the complete dialogue in detail) are typical examples of this feature. The agent explains the characteristics and advantages of the insurance in the discussion, and also compares it with other means of investment. Such turns have important implication for the sales. On one hand, it enables the agent to have control over the conversation as what to talk about and where this conversation goes; on the other hand, through the detailed introduction, the agent establishes an image of being professional and knowledgeable. More importantly, the agent acts as a friend, caring about the interests of the prospective client. This also has some implications for the prospective client, in that the message implied here is that the agent is my good friend, she is professional, she is caring about my interest and, more importantly, she is trustworthy. This kind of institutional talk has great significance for the successful conclusion of business. 
Institutional talk also needs to be carefully managed; otherwise, it may evoke resistance on the part of the client. This is how one of the agents included in this study describes her first successful conclusion of a substantial policy worth 4.5 million Yuan: "At a friend's party, the watches that the couple next to me wore caught my attention, they were of great value. I then talked to the wife for a while and we were really liked each other, so we left our contact and became friends. Later, I started to follow what she followed, such as economic news, company websites, etc.; and I used WeChat and SMS to introduce some concepts of insurance. For example, after I understood her needs, I managed to strengthen the friendship by giving better service. I told her that insurance is one way to evade taxes, and that their wealth needs to be better managed, etc., while continuing to offer high quality service" (Personal communication, February 15, 2013). This short, honest segment reveals that agents do indeed make careful analysis and preparation for institutional talk. They identify prospective clients' needs and relate these needs to the products they are selling. In actual conversations, such topics can be arranged in the form of institutional talk and thus the agents assume the identity of professional service providers. It is common in normal conversations between counterparts that both parties are supposed to contribute roughly equally to the topic of discussion. Instead, in this situation, one party dominates, which gives rise to another important type of talk; namely, task-oriented talk.

\subsubsection{Negotiation of Identity in Task-oriented Talk}

As good examples of task-oriented talk, turn 25 notes: "Yes, I have bought it for my husband and son and myself, our financial situation is not as good as yours, we couldn't buy too much, just like that, I have bought some though..." and turn 41 states: "Yes, exactly—let's do it this way, there will be a promotional reception at XX Hotel next Saturday, we will invite a lecturer there to introduce the products to us. There will even be presents if you sign on site, and a lottery. It does not matter if you don't want to make the decision yet, you can go and have a look then, I can take you there..." In turn 25, after several segments of long introductions in turns 17, 19, 21 and 23, after the prospect has already got some idea about the insurance via the discussion, the prospect attempts to strengthen his confidence in the policy by asking a question in turn 24: "Have you bought it yourself?" Given the simplicity of the question, the implication here could be significant. Even though the agent and client are friends and they are familiar with each other; when it comes to money, both need to be more careful. The prospect needs to make sure the insurance is safe and to his advantage. If the agent herself has also bought the insurance, then it should be no problem at all; otherwise, the prospect may consider more carefully. As argued earlier, the Chinese society is, to a certain extent, a Guanxi society, or more broadly, a society typified with Confucianism discourse system, in which particularistic trust plays a more important role in interpersonal relationship (Zhao, 2013; Huang, 2004; Zhai, 2011). Confucianism influences are deeply rooted in the Chinese culture, and have been argued to be one of the reasons that there is high level of particularistic trust and a lower level of generalized trust. Specifically, in the example above, whether the agent herself has bought the insurance is important and has become one of the focal factors which determine the prospect's decision in making the purchase.

In turn 41, after the prospect made his confidence in the agent clear, the agent makes a further attempt to invite the prospect to attend a seminar at a fancy local hotel. It is also presented in the way of being in the best interest of the prospect: "There will even be presents if you sign on site, and a lottery." The agent also leaves room for the prospect: "It does not matter if you don't want to make the decision," which gives the prospect an option to graciously decline, and for the agent to not to impose. Such flexibility also contributes to the successful conclusion of business.

From the above analysis, it can be seen that the conversation is constitutive of different types of talk, which indicates the shifts and mediation of different frames. The conversations mostly start with friendship talk, followed by institutional/task-oriented talk, and end with friendship talk. More specifically, if there is some kind of stalemate or difficulties in the institutional talk/task-oriented talk, the agent would shift back to friendship talk consciously or unconsciously to maintain the harmony and rapport between the agent and client. Meanwhile, sometimes the client also manages to shift between different types of talk to his/her own advantage due to lack of interest, while still maintaining the harmonious atmosphere in the interaction. Therefore, shifts and mediation of different frames unveil the dynamics of the interactions between agent and client, and they also offer an illustration of friendship (Kong, 2008; Zhai, 2011; Huang, 2004). Hence, in business and insurance sales discourse, insurance sales discourse is a platform for the mediation and contestation of business and friendship discourses.

Analyzing this segment of the conversation between the agent and the prospective client, this part examines in detail how identities in insurance sales are inter-actionally maintained, contested, and managed through changes in footing, interactive frames and discourse identities. As already argued, identities are not preordained. Rather 
than being imposed by one of the parties concerned, they are maintained, ratified, contested, and inter-actionally managed. Moreover, since power is an inherent feature of all interactions, it is demonstrated that in insurance sales, power is never a stable element, but rather is subject to negotiation, especially in the increasingly common situations in which power structure is not well-defined. In insurance sales interactions, the identities can be complex and overlapping.

\subsection{Footing in Different Types of Talk}

From turn 1 to turn 9, both participants exhibit a different footing; that is, the friendship footing, as shown by a topic change. The topic they turn to is an informal one about the agent's job: "I'm with XX life insurance." The change of footing is also accompanied by a change in prosodic features. Both of them are rather casual and tend to speak more slowly and use more emotional markers. The average rate of characters per second for the agent in this casual talk is about 5 characters per second, while in the institutional talk that follows in turn 17 , the rate is about 7 or 8 characters per second. This feature of friendship talk is the opposite of what Tannen (2005) found in her study of interactions among middle-class American acquaintances. Is it due to cultural differences in friendship? Or it is just not representative of the real interactions between friends in the Chinese context? It could be that the rate of speech alone is not a defining feature of friendship talk, but indicates the contrast with the previous type of talk. Due to the fact that if both of them already speak very fast in friendship talk, it would be virtually impossible to speak even faster in the following task-oriented talk and institutional talk. Thus, what they can do is to speak more slowly to distinguish between their friendship talk and other types of talk.

In the above interaction, mostly in the institutional talk and task-oriented talk, the agent tends to be rather indirect in her efforts to make the sales. This is in contrast to the regulating and controlling that an employer and employees in ordinary work settings do (Gabrenya \& Hwang, 1996; Kong, 1998; Pan, 1994). Even though the agent's husband is the director of the village and her father and brother are both locally well respected doctors, she does not possess the legitimacy in regulating and controlling the prospect. Therefore, she initiates the actual sales effort by starting very indirectly with the introduction of a third party both participants are familiar with. In turn 9: "Well, I heard that teacher Liu talked to you about insurance, what did you say?" She also asks and answers several questions pertaining to the issue of insurance in the discussion: "What kind of insurance do you do?" "What we are introducing here is a kind of investment by small amounts..." This resembles advice given by a friend more than a command given by a superior to a subordinate. In order to make her sales pitch stronger, she makes a more detailed introduction of the features of the insurance in turn 17 in the discussion, specifically the bonus type insurance. In order to reduce the imposition, she carefully formulates the introduction into examples and figures, which are much more tangible and more easily understood by the prospect.

Despite the careful formulation of the sales by the agent, the prospect still sees it as a face-threatening move. Naturally, resistance and hesitation are possible after long segments of institutional talk and task-oriented talk. Turn 26, "Your husband XX is still working at the village office?" marks a clear signal of the prospect's resistance and reluctance. By this statement, a rather abrupt change of topic, a change in footing from "business" to "friends" is made. The prospect's discourse identity has also been shifted to the related discourse identities a friend can assume in an interpersonal interaction. By changing to the friendship identity, the prospect's construct of self (the principal) cannot be challenged, in the sense that his own personal experience and relations should be respected by his friend. This strategic shift of footing is cooperatively echoed by the agent, who co-constructs cooperatively the friendship talk with the prospect in the next two turns (turns 27 and 29). Until turn 31, after responding to the second casual question about the agent's son, "Yes, in Guangzhou, that disobedient boy..." there is a short pause for about two seconds. This pause is a contextualization cue (Gumperz, 2001) to indicate the agent's effort to resume the previous topic of insurance, and to continue to convince the prospect to purchase another type of insurance designed for the prospect himself instead of his children.

As shown in the above segment, friendship talk is as "goal-oriented" as other types of talk. Both participants see the identity in question as a strategy to achieve their respective goals. Nevertheless, the nature of the goals in this talk category is different. While the goals of task-oriented and institutional talk are to get something done, the goal of friendship talk resembles that of ordinary conversations among friends in terms of reciprocity and topic contribution. Friendship talk can here also serve as an important lubricant to get things done, supporting the claim that no interaction is power-free.

In task-oriented talk, there is a mismatch of different discourse systems and frames, as illustrated in the following figure: 




Figure 1. Mismatch of discourse systems and frames in task-oriented talk

The indecision of the client in buying the promoted insurance policy due to various reasons is not expressly stated. Rather, this is indicated and inferred in the hesitation, unwillingness to continue with the current topic or, sometimes, long pauses or abrupt interruptions to change the topic. As in the discourse system of friendship, it is expected that the client should be supportive and cooperative, while if it is interpreted in the discourse system of institution, then business is business and friends are friends; they are two completely different realms. In the meantime, the confrontation and conflict between different discourse systems have become a site of struggle for the mediation of different frames and identities, in which the participants manipulate the frame to the advantage of the identity they are constructing. Therefore, it can be argued that the inter-discursivity of discourse systems can be strategically employed not only by business enterprise and their representatives (agents), but also by their (prospective) clients, who can play an active role in resisting agents' profit-making interests. According to the interviews with one of the agents, among about 100 of her clients, about 90 are working away from their hometown and earning their living in large cities. About 10 are employed with local factories or working in various service sectors, while only a few of them are working as farmers. This occupational distribution is similar to clients of other agents (Personal communication, August 2013). Another feature of the relationship between the agents and their (prospective) clients is that they know each other, sometimes very well. They are either relatives, friends or home fellows; at least they are referred to each other by a third party with whom both of them are familiar. As one of the respondents said in the interview: "I started selling insurance in 2002, at that time, my cousin (my aunt's daughter) was doing it, and they were planning to set up a network here at Daihui. She then introduced me. After some time, she left, I then continued to do it. In the beginning, it happened just on this street, they $<$ clients $>$ are all neighbors, you know. I was raising a child, so I only focused on this street, we were familiar" (Personal communication, June 6, 2010).

This account is echoed by the second respondent (an existing client) in the interview: "My first purchase was in 2002 , at that time, he <the agent> had a difficult time. He had a heavy burden with the old and also the small to care for. He just started selling and was not doing well. He then came to me, I just bought one. Just after that, he began to do well, a large group of people around me all bought one" (Personal communication, August 20, 2010).

Interviewer: "Then it's a policy purchased mostly out of consideration of trust and friendship?"

Respondent: "Yes, it is. But later, it turned out it was good; I then bought some for my child. As long as it's affordable, it's good."

To expand on the findings in this study, it can be argued that modern Chinese are undergoing profound changes in their relationship orientations, from more collectivistic to more individualistic, as seen in the mixing and crossing of in-group and out-group domains. Nonetheless, more cross-cultural studies are necessary, both between rural Chinese and other non-Chinese cultures, as well as between rural Chinese- and non-rural Chinese-dominated cultures (such as urban Chinese) in order to confirm the findings.

In conclusion, this section has illustrated the complex nature of identities. Both interactional sociolinguistics and conversation analysis have been employed to examine how participants construct identities for accomplishing 
interactional goals. The notions of footing, interactive frames, contextualization cues and discourse identities in interactional sociolinguistics are useful in examining how participants mobilize the interactional devices available to them for invoking the identities favorable to them. Meanwhile, the conversational analysis of turn-taking and interruption patterns show how identities can be co-constructed and contested. Both interactional sociolinguistics and conversation analysis bear the assumption that language can shape and be shaped by the context. Conversation analysis is mostly focusing on studying participants' sense-making practices through sequential devices, without paying much attention to the interactional devices within utterances. Interactional sociolinguistics, on the other hand, focuses more on the interactional properties of verbal and non-verbal signals. The above analysis attempts to integrate the two in an effort to make the analysis more thorough and complete.

\section{Discussion}

This article investigates the dynamics of agent-client interaction through interactive devices such as changes in footing, frames, and discourse identities through the analysis of different types of talk. Friendship identity is often invoked by friendship talk at the beginning of interactions, which is useful in maintaining the interpersonal ties and downplaying the business-oriented aspects of the participants' activities. Agents may initiate an institutional talk by invoking the corresponding identity in order to control and justify their action. In the meantime, the client can invoke friendship talk to justify their action or inaction. Their interactions always end with a friendship talk to reinforce their friendship and rapport.

More specifically, this study illustrates the dynamics of insurance sales in transformational rural China. Agents of insurance sales in rural China exploit the intersection between friendship and business. Nevertheless, as agents can employ friendship talk to create meanings, so can clients in order to evade and justify their actions or inactions. In short, both agents and clients can use friendship talk for their own respective interactional advantages. Moreover, identities can be the products of mobilization by human agents rather than preordained entities, and can be invoked linguistically for interactional purposes.

Through linguistic resources, insurance sales agents are able to strike a balance between the pragmatic business purpose and the personal emotion style, and they try to convince not only their prospective clients but themselves that insurance sales through Guanxi is a socially acceptable and legitimate activity. Beliefs and emotions are commercialized and even manipulated to serve the purpose of a successful conclusion of policy sales, supporting the sociological argument of insurance sales as "the business of belief" (Biggart, 1989). After all, from the above analysis, it can be seen that insurance sales agents are eager and deliberate in trying to employ linguistic resources to give meaning and construct appropriate identities for themselves, which indicates that insurance sales as a social activity is still built upon a weak foundation and yet to be widely accepted, let alone appreciated.

Due to the fact that an important task of post-modern enterprise is to reconcile the business goals of the company and the personal needs of their individual employees, there are corresponding changes in discourse as well. It has been recognized that traditional bureaucratic control measures are no longer appropriate and effective in satisfying employees' needs for searching for meaning. Such changes have been characterized by the shift from the rational bureaucratic control discourse to "entrepreneur of self" discourse (Du Gay, 1996), in which employees are encouraged to be autonomous and self-regulating individuals. Such an identity is argued to be constructive to both entrepreneurs and employees themselves. Nonetheless, changes in discourse do not necessarily mean a total disappearance of power, but only changes in power structure (Foucault, 1977), as argued by Wodak (1995) that there is basically no power-free discourse. In the context of insurance in rural China, the insurance companies still enjoy the power advantage since they are in a more advantageous position to ascribe meanings to, and define identities for, their institutional benefits. Given the fact that insurance sales agents are encouraged to be the "entrepreneurs of self," they do so more for the benefit of the institution than for themselves, as they are not equipped with enough means to do so. They at most accept and identify themselves with the meanings, practice them and transmit such meanings in their interactions with others. In the Chinese rural insurance context, agents work for their companies, but with a different label(Most of them work on part-time basis). By exploiting and commercializing peoples' beliefs and trust through linguistic resources, insurance companies and their agents are attempting to construct an identity for themselves as organizations that are doing "social good" for the society and offering a new form of self for their agents. However, with the inherent problems in the insurance sales system, such as lack of an effective selection system and sufficient training, insurance sales may produce even more disappointment, helplessness, frustration and fragmentation of individual identities. 


\section{Acknowledgment}

This paper is part of research on A Study of the Realization of Discursive Power in the Legal Cases of Fund-raising on the Part of China's Private Enterprises: the project of 2014 Guangdong Provincial Philosophical and Social Science Program GD14XWW22.

\section{References}

Askehave, I., \& Swales, J. M. (2001). Genre Identification and Communicative Purpose: A Problem and A Possible Solution. Applied Linguistics, 22, 195-212. https://doi.org/10.1093/applin/22.2.195

Baker, T., \& Simon, J. (2013). Embracing Risk: The Changing Culture of Insurance and Responsibility, Chicago Scholarship.

Bargiela-Chiappini, F. (2009). The Handbook of Business Discourse. Edinbourgh: Edinburgh University Press.

Beck, U. (1992). Risk Society: Towards a New Modernity. London: Sage. http://dx.doi.org/10.4135/9781412952552.n244

Bhatia, V. K. (2005). Generic Patterns in Promotional Discourse. In H. Halmari, \& T. Virtannen (Eds.), Persuasion across Genres: A Linguistic Approach. Amersterdam/Philadelphia: John Benjamins Publishing Company. http://dx.doi.org/10.1075/pbns.130.13bha

Boden, D. (1983). Talk International: An Examination of Turn-taking in Seven Indo-European Languages, Paper presented at the American Sociological Association Meetings, Detroit.

Brown, P., \& Levinson, S. C. (1987). Politeness: Some Universals in Language Usage. Cambridge: Cambridge University Press.

Cameron, D., McAlinden, F., \& O’ Leary, K., (1988). Lakoff in Context: The Social and Linguistic Functions of Tag Questions.

Cao, H. X. (2009). A Discussion on China's Insurance Marketing System Reform, Management Observer.

Cao, J. Q., \& Chen, Z. Y. (1997). Walking out of the Ideal Castle: Study on the Chinese "Danwei" Phenomenon. Shenzhen: Haitian Press.

Cheng, W. (2003). Intercultural Conversation. Amsterdam and Philadelphia: John Benjamins. https://doi.org/10.1075/pbns. 118

Chua, R. Y. J., Morris, M. W., \& Ingram, P. (2009). Guanxi VS Networking: Distinctive Configurations of Affect- and Cognition-based Trust in the Networks of Chinese VS American Managers. Journal of International Business Studies, 40, 490-508. http://dx.doi.org/10.1057/palgrave.jibs.8400422

Diana, B. (2002). Applying Sociolinguistics. John Benjamins.

Ding, Z. S., (2008). A Study on China's Insurance Market Development, Insurance Studies.

Don, Y. L., \& Philip, L. D. (2005). Trust, and Long-Term Orientation in Chinese Business Markets. Journal of International Marketing, 13(2), 28-56. https://doi.org/10.1509/jimk.13.2.28.64860

Drew, P., \& Heritage, J. (eds.) (1992). Analyzing Talk at Work. In P. Drew, \& J. Heritage (Eds.), Talk at Work: Interaction in Institutional Settings (pp. 1-65), Cambridge: Cambridge University Press.

Duranti, A. (1998). Ethnography of Speaking: Towards Linguistics of the Praxis. In F. J. Newmyer (Ed.), Linguistics: The Cambridge Survey (Vol. VI, pp. 210-228) Language: The Socio-Cultural Context. Cambridge: Cambridge University Press. http://dx.doi.org/10.1002/9780470758434.ch2

Eggins, S., \& Slade, D. (1997). Analyzing Casual Conversation. London: Cassell.

Ericson, R., \& Doyle, A. (2004a). Uncertain Business: Risk, Insurance and the Limits of Knowledge. Toronto: University of Toronto Press.

Ericson, R., \& Doyle, A. (2004b). Catastrophe Risk. Insurance and Terrorism, Economy and Society, 33, 135-173. http://dx.doi.org/10.1080/03085140410001677102

Ericson, R., \& Doyle, A. (2004c). Criminalization in Private: The Case of Insurance Fraud, in Law Commission of Canada, ed., What is A Crime? Defining Criminal Conduct in Contemporary Society, 99-124. Vancouver: University of British Columbia Press.

Ericson, R., \& Doyle, A. (2003). Risk and Morality. Toronto: University of Toronto Press.

Fei, X. T. (1999). The Development Path of China's Urban and Rural Areas-The Research Project of My Life, 
in Vol. 12 of Collections of Fei Xiaotong, Beijing: Qunyan Publishing.

Fei, X. T. (2007). From the Soil: The Foundations of Chinese Society, Jiangsu Literature and Arts Publishing.

Goffman, E. (1967). Interactional Ritual: Essays on Face-to-Face Behavior. New York: Doubleday Anchor.

Goffman, E. (1981). Forms of Talk. Pennsylvania: University of Pennsylvania Press.

Gumperz, J. (1982). Discourse Strategies. Cambridge: Cambridge University Press. http://dx.doi.org/10.1017/CBO9780511611834

Gumperz, J. (1982). Language and Social Identity. Cambridge: Cambridge University Press. http://dx.doi.org/10.1017/CBO9780511620836

Gumperz, J. (2001). Interactional sociolinguistics: A personal perspective. In D. Schiffrin, D. Tannen, \& H. Hamilton (Eds.), The handbook of discourse analysis (pp. 215-228). Malden, MA: Blackwell. http://dx.doi.org/10.1002/9780470753460.ch12

Guo, Y. (2009). A Brief Survey of China's Insurance, Modern Economy.

Hayashi, M. (2003). Joint Utterance Construction in Japanese Conversation, Amsterdam and Philadelphia: John Benjamins. http://dx.doi.org/10.1075/sidag.12

Heritage, J. (1984). A Change-of-state Token and Aspects of Its Sequential Placement. In J. M. Atkinson, \& J. Heritage (Eds.), Structure of Social Action: Studies in Conversation Analysis (pp. 299-345). Cambridge: Cambridge University Press. http://dx.doi.org/10.1017/CBO9780511665868.020

Hu, W., \& Wang, H. (2009). The Scientific Development of Insurance Industry from A Sociological Perspective, Insurance Studies.

Huo, Y. S. (2004). Mitigation and Pragmatic Adaptation: A Case of Interviews in Traditional Chinese Medicine. Yunnan University Press.

Hutchby, I., \& Wooffitt, R. (1998). Conversation Analysis. Cambridge: Polity Press. http://dx.doi.org/10.1075/hop.m.con4

Jefferson, G. (2004). Glossary of Transcript Symbols with an Introduction. In G. Lerner (Ed.), Conversation Analysis: Studies from the First Generation, Amsterdam: John Benjamins. http://dx.doi.org/10.1075/pbns.125.02jef

Kong, C. C. (2001). Marketing of Belief: Inter-textual Construction of Network Marketers Identity. Discourse and Society, 11(4), 473-503. https://doi.org/10.1177/0957926501012004004

Kong, C.C., (2002), Managing the Ambiguous and Conflicting Identities of "Up-line" and "Down-line" in a Network Marketing Firm. Discourse Studies, 3(4), 49-74. https://doi.org/10.1177/14614456020040010301

Kong, C. C. (2003). Are You My Friend?: Negotiating Friendship in Conversations between Network Marketers and Their Prospects. Language in Society, 32, 487-522. https://doi.org/10.1017/S0047404503324029

Li, G. X. (2008). The Marketing Mechanism of China's Insurance, Economic Forum.

Liang, Y. (2011). Civil Legislative Concept of Particularistic Trust-A Perspective Based on Two Consecutive Studies, Xuehai Press.

Lin, H. D. (2004). Initiating, Sustaining, and Concluding Social Transactions: An Analysis of Role-play Performance in the Oral Proficiency Interview. Journal of Language and Linguistics, 3, 109-137.

Lu, X. Y. (2002). A Research Report on Contemporary China's Social Strata. Beijing: Social and Scientific Literature Publishing.

Luke, K. K. (1990). Utterance Particles in Cantonese Conversation. Amsterdam and Philadelphia: John Benjamins. http://dx.doi.org/10.1075/pbns.9

Luo, J. D., \& Ye, Y. Z. (2007). Trust Game of the Chinese. Beijing: Social and Scientific Literature Publishing.

Malinowski, B. (1923). The Problem of Meaning in Primitive Languages. In K. O. Charles, \& I. A. Richards (Eds.), The Meaning of Meaning (pp. 146-152). London: Routledge.

McAra-McWilliam, I., \& Casalegno, F. (2004). Communication Dynamics in Technological Mediated Learning Environments. International Journal of Instructional Technology and Distance Learning, 1(11), 15-34.

Montgomery, B. M. (1988). Quality Communication in Personal Relationships.

Planken, B. (2005). Managing Rapport in Lingua Franca Sales Negotiations: A Comparison of Professional and 
Aspiring Negotiations. English for Specific Purposes, 24, 381-400. http://dx.doi.org/10.1016/j.esp.2005.02.002

Punch, K. F. (1998). Introduction to Social Research. London: Sage.

Riggs, F. W. (1964). Administration in Developing Countries. Boston: Houghton Mifflin Company.

Roger, D. (1989). Experimental Studies of Dyadic Turn-taking Behavior. In D. Roger, \& P. Bull (Eds.), Conversation (pp. 75-95). Philadelphia: Multilingual Matters.

Rogers, L. E., \& Millar, F. E. (1988). Relational Communication.

Sacks, H. (1974). An Analysis of the Course of a Joke's Telling in Conversation. In R. Bauman, \& J. Sherzer (Eds.), Explorations in the Ethnography of Speaking (pp. 337-353). Cambridge: Cambridge University Press.

Schegloff, E. A. (2000a). Overlapping Talk and the Organization of Turn-taking for Conversation. Language and Society, 29(1), 1-63. http://dx.doi.org/10.1017/S0047404500001019

Schegloff, E. A. (2001). Accounts of Conduct in Interaction: Interruption, Overlap and Turn-taking. In J. H. Turner (Ed.), Handbook of Sociological Theory (pp. 287-321). New York: Plenum. http://dx.doi.org/10.1007/0-387-36274-6_15

Schiffrin, D. (1990). The Management of a Co-operative Self during Argument: the Role of Opinions and Stories. In A. D. Grimshaw, (Ed.), Conflict Talk: Sociolinguistic Investigations of Arguments in Conversations (pp. 241-259). Cambridge: Cambridge University Press.

Scollon, R., \& Scollon, S.W. (2001). Intercultural Communication: A Discourse Approach. Blackwell Publishers.

Shegloff, E. A. (2000b). When "Others" Initiate Repair. Applied Linguistics, 21(2), 205-243. https://doi.org/10.1093/applin/21.2.205

Sheng, Z. (2009). Retrospect on the Chinese Insurance Market Development in 2008, China Insurance.

Shu, J., \& Li, J. (2006), Moral Risks and Commissioning in Insurance-Agent Model, Journal of Chongqing Institute of Technology.

Strange, S. (1996). The Retreat of the State: The Diffusion of Power in the World Economy. Cambridge: Cambridge University Press. http://dx.doi.org/10.1017/CBO9780511559143

Sun, L. P. (2009). The Remaking of Society—Order Reconstruction in Transformational Society. Beijing: Social and Scientific Literature Publishing.

Swales, J. M., \& Rogers, P. S. (1995). Discourse and the Projection of Corporate Culture: The Mission Statement. Discourse \& Society, 6, 223-242. http://dx.doi.org/10.1177/0957926595006002005

Swales, J. M. (2004). Research Genres: Explorations and Applications. Cambridge: Cambridge University Press. http://dx.doi.org/10.1017/CBO9781139524827

Swales, J. (1991). Genre Analysis-English in Academic and Research Settings. Cambridge: Cambridge University Press.

Tanaka, H. (1999). Turn-taking in Japanese Conversation: A Study in Grammar and Interaction. Amsterdam and Philadelphia: John Benjamins. http://dx.doi.org/10.1075/pbns.56

Tang, M., \& Huhe, N. (2014). The Variant Effect of Decentralization on Trust in National and Local Governments in Asia. Political Studies.

Van, D., \& Teun, A. (2006). Discourse and Manipulation, Discourse and Society (pp. 359-383). Sage Publications. http://dx.doi.org/10.1177/0957926506060250

Xu, X. (2009). An Exploration of Overseas Academic Studies on Issues of China's Insurance Industry, Shanghai Insurance.

Yang, M, (1994). Gifts, Favors, and Banquets: The Art of Social Relationships in China. NY: Cornell University Press.

Yang, Z. F., \& Peng, S. Q. (2009). The Conceptualization of Chinese Interpersonal Trust-An Interpersonal Relational Perspective. Journal of Sociology Studies.

Yuan, L. (2008). Current Situations and Problems of Insurance Agent System in China. Modern Economy. 
Zhai, X. W. (2007). The Operating Mechanism of Bao. Journal of Sociology Studies.

Zhai, X.W. (2009). Guanxi, or Social Capital. Society, 29.

Zhao, J. G. (2013). A Critique on Chinese Guanxi. Xinhua Press.

Zhou, X. H. (2014). Social Mentality in Transforming era and Chinese Experience. Journal of Sociology Study, 4.

Zhu, J. (2009). Prospect of Chinese Insurance Market 2009, China Insurance.

Zimmerman, D. H. (1988). On Conversation: the Conversation Analytic Perspective, Communication Yearbook II, 406-432, Newbury Park: Sage. http://dx.doi.org/10.1080/23808985.1988.11678699

\section{Appendix}

\section{The Reconstructed Dialogue between the Agent and the Client}

A: agent B: prospect

1. A: Jintian Zaijia Xiuxi a? (Having one day off at home today?)

2. B: An, Zai Jiali Wan. (Yeah, one day off at home.)

3. A: O, Liu Laoshi Yuanlai Nimen Han Jiefu Hei? (Oh, by the way, you call Teacher Liu brother-in-law?

4. B: Shide O. (Yes, exactly.

5. A: Ta Yuanlai Jiushi Women Laoshi Ai. (He used to be our teacher... 1 second pause)

O, Liangge Maomao, Hei? (Oh, you have two children, then?)

6. B: En, Zai Jiali Peidu. (Pause, half a second)

Nishi Baoxian Gongsi de A? (You work with the insurance company?)

7. A: En, Woshi Zhongguo Renshou Gongsi de. Liudian de Wang XX Ni Ke Rende? Liudian Nage Yisheng a, Woshi ta Jiejie. Ni Laopo Zai Songshuke, Women Gebi Shengchandui Ma. (Yes, I work with China Life. Do you know Wang XX from Liudian? That doctor at Liudian, I am his sister. Your wife is from Songshuke, a neighboring production unit of ours.)

8. B: En. (Yes.)

9. A:Hehe, Wo Zuotian Ting Liu Laoshi Jiang Gaobaoxian, (Ta) Gen Nimen Zenme Jiangde A? (Well, I heard that Teacher Liu talked to you about insurance, how did you talk?)

10. B: En, Yemei Zenme Jiang, Jiushi Jiang Jiu Jiangqitou Laile. Jiujiang Zhe Baoxian Na Baoxian, Jiang Baoxian Zhonglei Haoduo...(Well-- We didn't talk that much, it's generally about this insurance, that insurance, there are many types of insurance...)

Half a second pause.

11. A:En, Na Shide $O$. (Well, yes, that is certainly true.)

12. B: Nimen Bande Shi Shenme Baoxian Ne? (What kind of insurance do you do?)

13. A: Women Bande You Xiaojiaohuo de Jiaoyu Baoxian, Chengzhang Baoxian'a Xuduo de. (We have education insurance, growth insurance etc. for the kids.)

14. B: Xiaojiahuo Zai Xuexiao Nianshu Bushi Yijing You Baoxian lema? (But haven't they already got insurance covered at school?)

15. A: Bushide, Nage Baoxian Qian Shi Butui Geini de, Women Geini Jieshao de Baoxian, Shi Jishao Chengduo, Yicixing Bani Haishi Sanci Bani, Bini Cun Yinhang Lixi Gao. (No, it's not that kind of insurance. For that insurance, you won't get reimbursement. What we are introducing here is a kind of investment by small amounts. Later you will get the reimbursement once or in three times. The earning rate is higher than that you save it with the banks.)

16. B: Shenme Xianzhong $a$ ? (What kind of insurance is that?)

17. A: Ruguo Nigei Maomao Maide Hua, Ruguo Canjia Fenhong, Fenhong You Benjin Leiji Shengxi. Juti Qingkuang Wo Geini Jieshao Xiazi, JiaruJiang Women Mai Shiwan de Nazhong, Fen Shinian Jiao, Yinian Jiushi 
Jiao Yiwan, Jiarujiang Women Diyinian Jiaole Yiwan, Zhe Jiushi Nide Benjin, Benjin Fangna Yao Shengxi, Women Anzhao Qunian de Qingkuang, 5.6\% Laisuan, Yinian Jiushi 56; Diernian Kaishi Women de Benjin Jiushi 10560 Le, Zheshihou Zai Jiashang Ni Diernian Jiaode Baofei Yiwan, Najiushi 20560; Ranhou Disannian, Disinian, Yici Leitui, Jiushi jiang Li Shengxi, Gundong de, Dao Zuihou ne, Dengni Jiaoman Shinian le, Ni Keyi Xuanze Yicixing Na Huilai; Jiaru Jiang Ni Juede Lirun Haihao, Ni Yekeyi Jixu Fangna, Jiu Xiangshi Licai Yangde, Yezhong; Haiyou Biru Jiang Ni Meinian Xiangba Nage Fenhong Nachulai, Yezhong; Nani Jiushi Benjin Fangna, Fenhong Ziji Nahuilai Yong, Ye Yiyang...(If you buy it for your kids and there will be dividends, which is cumulative. Let me explain to you: Suppose we buy a 100,000 Yuan policy for ten year, that is 10,000 Yuan each year; and suppose we pay 10,000 for the first year, that is your principal, which will generate interest. According to the rate of last year, 5.6\%, it will make 560 Yuan; then for the second year we will have 10560 Yuan as our principal, plus the principal for the second year that you pay, it will make a total of 20560; then the third year, the fourth year, etc. , all in all, it's cumulative. Then finally, if you pay for ten years, you can choose to take it all back once and for all, or you can take it back for several times; furthermore, if you think the profit is good, then you also can choose to put it there, just like wealth management; otherwise, you can choose to withdraw the dividends...)

18. B: Na Jiaru Jiang Wo Zhongjian Xiangyao Yongqian, Na Zenme Gao a? (Then what if I need to use that money?)

19. A: Yongqian dehua Ne, Ni Zuihao Shi Budong Benjin, Benjin Yidong, Najiu Xiangdangyu Weiyue, Weiyue Dehua Nani Jiu Huabulai Le, Zhege Dongxi Women Yao Shihua Shishuo, Yinwei Women You Hetong, Nuo, Zhege Changzi, Ni Kankan. Nani Jiu Feichang Huabulai Le.(If you need to use that money, you'd better not withdraw the principal. Once you withdraw the principal, it's breach of contract, then you will suffer great losses. I need to be honest with you, since we have got the contract, look, here... then you will suffer great losses.)

20. B: O, Na Jiushi Jiang, Wo Maile Yihou Jiu Buneng Dongle... (Oh, that is to say, After the purchase, I cannot withdraw...)

21. A: Ye Bushi Name jiang, Yiban Mai Baoxian Women Bu Dushi Xianqian ma; Zanshi Meiyou Qita Bijiao Haode Difang Touzi a Huozhe Zenyang; Zaijiang Ni Jiali Zhege Qingkuang, Ye Buzhiyu a, Zhege Ye Buduo, Hehe, Nijiang Keshi de a ?( Not exactly that way, generally speaking, we buy insurance with some spare money, that is, no other better places to make the investment or other things; moreover, with your financial status, it's not too much, don't you think so?)

22. Aya, Nage Dongxi Nanjiang O...(Aya, it's hard to say...)

23. Wo Juede ne, Women Zheme Xiang, Xianzai Women Hai Bijiao Nianqing, Zhengqian Nengli Bijiao Qiang, Nianfu Liqiang de Shihou, Zhege Shihou Maidian Baoxian, Gei Women Xiaojiaohuo Youge Baozhang, Jiu Xiangshi Cunkuan Yangde, Deng Tamen Zhangda Le, Zui Qima Haiyou Name Yibiqian Zaina, Women Daoshihou Wanyi Jiangdehua, Nianji Dale, Zuo Budongle, Tamen Nengyong Zhe Yibiqian Haineng Zuo Yidian Shiqing; Zaijiang, Xianzai Qian Cun Yinhang Niye Xiaode, Meinian Tonghuo Pengzhang Name Lihai, Qian Shi Yuelaiyue Bu Zhiqian; Women Zhege Jiushijiang Yifangmian Ni Cunna You Lixi, Lingwai Yifangmian Women Gongsi Hai Naqu Touzi-XX Gongsi Niye Xiaode, Shijie Wubaiqiang, Zhongguo Zuida de Baoxian Gongsi, Ta Ba Zhege Qian Shouqilai Bushijiang Jiu Fangzai Na Huozhe Fang Yinhang, Ta Shiyao Naqu Touzi deai, Biru Jiang Xianzai Shenme Xibu Dakaifa, Fengli Fadian, Sanxia Gongcheng... Xuduo Xiangmu...(Well, let's put it this way, now that we are young and energetic, at this time if we buy some insurance it's like getting some assurance for our children, just like savings with the bank, when they grow up and we are old, we can still use that amount of money to do something; moreover, nowadays, you know if you save the money with the banks, with the high inflation rate, all the money will depreciate quickly; For our insurance, on one hand, you can have some interest with the money, on the other hand, our company will make investment with this pool of money, for example, invest in the project of developing the west China, wind energy, Project Three Gorges, and so on...)

24. ...Ni Kemai lema?(Did you buy?)

25. Wogei Wojia Ta He Erzi Haiyou Wo Ziji Du Maile a, Wojia Tiaojian Meini Zheme Hao, Maibule Taiduo, Jiu Zheyangzi, Wo Du Maile Bushao ne...(Yes, I have bought it for my husband and son and myself, our financial situation is not as good as yours, we couldn't buy too much, just like that, I have bought some though...)

26. Nijia XX Xianzai Haizai Cunli Gaoba? (Your husband XX is still working at the village office?)

27. An, Ta Bu Yizhi Zaina Changzi Xiamang ma. (Yes, he has always been doing that.)

28. Nahai Xiamang a, Zhuren Duohao, Buguo Shiqing Ye Queshi Duo. (Nonesense, it's good to be the director, but it's true that it is very busy if you take that job.) 
29. Shide a, Yitian Daowan Bu Guijia, Bu Xiaode Zaimang Shenme Dongxi. (Yeah, always working, not sure about what he is busy with.)

30. Oh, Ni Erzi Xianzai Shang Daxue Leba? Zai Guangzhou Haishi Zaina Keshi dea? (Oh, Your son is at university now, isn't he? In Guangzhou or anywhere?)

31. An, Zai Guangzhou, Nage Buchengqi de Dongxi... (Two seconds pause), Qishi Ni Yekeyi Kaolv Geini Ziji Mai Yidian ai, Nikan Ni Xianzai Zhengqian Duo, Danshi Women Guojia Xianzai Yanglao a, Shehui Baoxian a Zhe Yikuai Hai Buzenme Wanshan, Jianglai Nianji Dale, Women Bujiang Gei Xiaojiahuomen Chuangzao Duoda Jiazhi, Zuiqima Ziji Bao Ziji, Na Jiushi Gei Tamen Jianqing Fudan le, Nuo, Women Gongsi Xianzai You Yige Xianzhong Wo Geini Jieshao Xiazi a......(Yes, in Guangzhou, that disobedient boy... Actually you can think about buying some insurance for yourself, you see, you earn much now, but the fact is in China we don't have comprehensive social security, social welfare coverage. When we get old, if we can be self-sufficient and don't have to exert more burden on our children, that is already great contribution. By the way, our company offers one type of insurance that I can introduce to you...)

32. O? Women Yeyou a? (Oh, there is also insurance for us?)

33. Youa, You Yizhong Shi Women Zuijin Cai Tuichulai de, Zhuyao Zhendui San Sishisui, Xianzai Shouru Bijiao Haode Kehu, Ta Yeshi Baobenxing de, Jiushijiang, Buguan Zenme Gao, Ni Daozuihou Duneng Ba Benqian Nahuilai, Jiu Xiangdangyu Yizhong Chuxu, Ni Xiangxiangkan, Qian Cundao Yinhang, Xianzai Kending Bushi Yige Haoxuanze; Mai Fangzi, Xianzai Bujiang Qita Difang, Jiu Nanlingxian Zhege Xiaochangzi, Fangjia Du Yijing Gaode Budeliao le; Chaogu ba, Yeshi Fengxian Dade Budele—Wojia Nage Dangshi Maile Jiwan, Dao Xianzai Haimei Huiben; Women Zhege Xianzhong ne, Buguang Neng Baoben, Haineng You Fenhong, Duoshao Ni Keyi Genju Ni Ziji Qingkuang Xuan, Zuidi Qibu Wuwan, Shiwan, Ershi Wan, Sanshi Wan, Zuigao Wushi Wan, Maide Yueduo, Xiangduiying de Shouyi Yejiu Yueduo, Dagai Yiban Birujiang Shinian Yihou, Shiwan dehua Yiban Yigeyue Neng Nadao Yiliangqian Kuai Qian, Yigong Na Shinian, Ni Xiangxiangkan, Zhe Bujiu Dengyu Shangban Na Gongzi Lema?Zui Qima, Shenghuo Youde le...(Yes, of course. It is a recently released policy for those who have good earnings now at their 30 s or 40 s. It has principal guarantee, that is, no matter what, you can have your principal back in the end, so it is similar to deposit with banks. Just think about it, of course it is not a good choice to deposit your money with banks; as for buying property, let's not mention other places, just take Nanling County as an example, the real property prices are already very high; as to shares at the stock market, the risks are far too high — my husband bought some thousands at then and he is still suffering grave losses; And to our insurance policy, you can not only be sure of your principal, but also have some dividends, which will depend on the types of policy and amount you buy, starting from 50,000;100,000; 200,000; 300,000, tops at 500,000 , the more you buy, the more dividend you might have. Generally speaking, for 100,000, after ten years, you can have about one to two thousand Yuan for each month for consecutive 10 years, think about it, that is just like you are receiving salary from work, at least, it's enough for daily necessities...)

34. Oh, Na Zhege Hai Bucuo ne, Wo Yeshi Zai Kaolv, Xianzai Suiran Jiang Zhengdian Qian, Bu Wending a. (Oh, that is not bad, I am also thinking about that though I make some money now, it's not stable.

35. Shide a, Na Women Laijiang Jiushi Tiqian Zhunbei, Nage Chengyu Zenmejiang a, OH-Jiao Weiyu Choumou, Hehe, Fanzheng Zhe Dongxi, You Tiaojian, Gaoxiazi Haishi Haode, Qita Dongxi Wo Bugan Jiang, Zui Qima Wo Gaode Dongxi Wo You Xinxin, Qita Keneng Yeyou Yewuyuan Zhao le Ni ba? (Yes, for this it's precaution, there is one idiom for that, it's "In fair weather prepare for foul". Anyway, if possible, it's good to have some insurance. I'm not sure about other things, but I'm very confident in the things that I do now-Well, I suppose there are other agents approached you?)

36. An, You...(Yes, there was...)

37. Shide a, Qishi Zhe Dongxi Woye Buman Ni, Ni Maideduo Women You Ticheng, Danshi Wo Meici Du Genwo Kehu Jiangqingchu, Dajia Lide Buyuan, Youshu, Nijiang Keshi dea?(Yeah, well, I am very straightforward with you, I get more commission as you buy more, but I always make it clear and straight with my clients. We live close to each other and are so familiar, right?)

38. Na Shide O, Qita Ren Shi Ye Zhaoguo Wode, Wo Dangshi Jiujiang Bu Liaojie, Kankan Zaijiang, Hehe... (That is certainly true, there were other people approached me, and I just said I was not interested, hehe...)

39. Fanzheng Zhe Yidian Ni Fangxin, Wo Zai Zhechangzi Ye Zheme Duonian le, Dajia Dushi Taitou Bujian Ditou Jiande, Nazhong Shiqing Wo Zuo Bu Chulai. (No matter what, you can be sure of one thing, that is, I have been living here for long, we always run across each other, I won't do anything deceiving.)

40. Nawo Fangxin nuo-Yaobushi Nilai, Won a Tingni Jiang Zheme Bantian ne, Nijiang Keshi di. (I don't have 
a problem with that-if it is not for you, I won't even be listening for so long, right?

41. Na Shide o-Yaobu Ni Zheyangzi, Women Gongsi Xiage Xingqiliu Zai XX Jiudian Gaoge Xuanjianghui, Daoshi Women You Shengli Qinglai de Jiangshi Jieshao Chanpin, Xianchang Qianyue dehua Haiyou Lipin, Haiyou CHoujiang Huodong, Fanzheng Daoshi Ni Buxiang Mai Yebu Yaojin, Ni Yaoshi You Shijian dehua Jiu Guoqu Kankan, Wo Dai Nimen Yiqi...(Yes, exactly—let's do it this way, there will be a promotional reception at XX Hotel next Saturday, we will invite a lecturer here to introduce the products to us. There will even be presents if you sign at site, and lottery. It does not matter if you don't want to make the decision yet, you can go and have a look then, I can take you there...

42. Xiage Libailiu a? O, Wo Jianghao Yaodao Jieshang Qu, Jidianzhong a?(Next Saturday? Oh, I will also go to the market that day, what time exactly?)

43. Shangwu Jiudianban, Zheyangzi, Wo Badianban Daozhe Lai Jieni, Women Yiqi Guoqu, XX Jiudian Niye Xiaode, Haishi Bucuo dea, Zhongwu Women You Zhaodaihui, Gongsi Qing Chifan. (Nine thirty in the morning, I can pick you up here at eight thirty, we can go together. You know XX Hotel, a nice hotel. The reception lunch is on our company.)

44. Oh, Nahao a. (Oh, that's good.)

45. Hao, Najiu Zheme Jiang, Woxian Geini Zuoge Dengji...(All right, then. Let me get you registered...)

46. An. (OK)

47. Aye, Ni Jiali Zhe Zhuangxiu Gaode Zhenhao, Zhen Piaoliang, Shang Dangci, Huale Bushao Qian ba? (WOW, You have very nice decoration at your home, it's so beautiful and of class, you must have spent heavily.)

48. Zhege a, Women Zai Waitou, Yinian Bu Huilai Tangba, Wo Laopo Jiang Ziji Zhude Changzi Yao Gaohao Yidian, Shufu Xiema. (Well, we work far away from home and don't get home once or twice. And my wife said it is a better idea to make sure where we live comfortable.)

49. Na Shidi O, Ziji Zhu, Gaohao de, Meitian Zai Limian, Xinqing Du Buyiyang, hehe...(Exactly, to make it more comfortable. You will certainly feel better living inside...)

50. Na Yeshi de, Suoyi Nashihou Tajiang Yaogao, Wo Xiangxiang, Gao Jiu Gao ba, Fanzheng Dushi Ziji Zhu, Women Zai Waimian Bijing Yebu Changjiu, Zongshi Yao Huilai de, Keshi dea? Huilaide, Bijing Zenmeyang Yeshi Ziji Yige Wo a...(Yes, so when she said we decorate for the better, I thought about it and agreed. After all, we won't work far away forever, we will be back and we can have at least some small but cozy place of our own...)

51. An, Na Nimen Xiangde Shi Duide O (Yes, I totally agree with you.)

\section{Copyrights}

Copyright for this article is retained by the author(s), with first publication rights granted to the journal.

This is an open-access article distributed under the terms and conditions of the Creative Commons Attribution license (http://creativecommons.org/licenses/by/4.0/). 